\title{
Preparation and evaluation of chitosan-calcium-gellan gum beads for controlled release of protein
}

\author{
Fei Yang $\cdot$ Shuqin Xia $\cdot$ Chen Tan $\cdot$ \\ Xiaoming Zhang
}

Received: 12 March 2013/Revised: 3 May 2013/Accepted: 8 May 2013/Published online: 23 May 2013

(C) The Author(s) 2013. This article is published with open access at Springerlink.com

\begin{abstract}
The bead system composed of chitosan and calcium-gellan gum was prepared through a combination of ionotropic gelation and polyelectrolyte complexation for oral protein delivery. The characteristics of beads were investigated by scanning electron microscopy, Fourier transform infrared spectroscopy, differential scanning calorimetry, X-ray diffraction, release studies, and swelling measurements. It was found that chitosan endowed the calcium-gellan gum beads a dense surface and the crystal structure of polymers was disrupted after being combined together. The encapsulation efficiency of protein was in the range of $65-85 \%$. Higher gellan gum concentration combined with vacuum dryness significantly retarded protein fast release at $\mathrm{pH} 1.2$ and achieved sustained release at $\mathrm{pH} 6.8$, whereas providing efficient release at $\mathrm{pH}$ 7.4. The protein release was mainly attributed to Fickian diffusion mechanism in the process of swelling. The chitosan-calcium-gellan gum beads have the potential to act as a new carrier for controlled release of protein-based functional ingredients.
\end{abstract}

Keywords Chitosan · Gellan gum · Bovine serum albumin $\cdot$ Beads $\cdot$ Controlled release

\section{Introduction}

The oral route is the most convenient means for the administration of most protein-based functional

F. Yang $\cdot$ S. Xia $(\bowtie) \cdot$ C. Tan $\cdot$ X. Zhang

State Key Laboratory of Food Science and Technology, School

of Food Science and Technology, Jiangnan University,

Lihu Road 1800, Wuxi 214122, Jiangsu, China

e-mail: sqxia2011@yahoo.cn ingredients. However, there are some obstacles for overcoming due to their susceptibility to digestive enzymes in the gastrointestinal (GI) tract and limited ability to transport across the intestinal epithelial barrier [1,2]. Therefore, the development and utilization of delivery systems have attracted great interests in the past decade, which could protect protein from the GI environment and achieve controlled release.

The colon has been considered as an ideal site for protein and peptide absorption [3]. In the design of colonspecific delivery system of water-soluble and active ingredients, natural polysaccharides, such as pectin, alginate, chitosan, cellulose, and starch, are being preferred to their synthetic counterparts. Among these polysaccharides, gellan gum is a linear anionic polysaccharide obtained from the exocellular secretion of the microorganism, Pseudomonas elodea [4]. Except for low toxicity and biodegradability, gellan gum is very stable over the wide $\mathrm{pH}$ range of 2-10 [5] and insensitive to pectinase, amylase, cellulase, papain, and lipase [6], whereas it undergoes significant degradation in the presence of galactomannanase which in turn facilitates the core material release from beads in the colon fluid, thus approving the suitability of gellan gum as a carrier for controlled colonic delivery [7].

However, these natural polymers exhibit some limitations, such as uncontrolled hydration rate which could be reduced by modifying the solubility by cross-linking or complexation [2]. The commercially deacylated gellan gum (low acyl form) has a stronger affinity for divalent cations and its gel-forming ability at concentrations remarkably lower than other hydrocolloids such as alginate and pectin [8]. Due to its ability to form hydrogel in the presence of divalent cations, especially $\mathrm{Ca}^{2+}$ ions, gellan gum has been investigated for the controlled release of some drugs such as in situ gelling systems for ocular [9] 
and nasal [10] delivery. Although calcium-gellan gum beads are promising for colonic-specific delivery, the burst release is serious and sustained-release effect is very poor [4]. In order to address the problem, Maiti et al. [11] developed a system through ionotropic gelation of gellan with $\mathrm{Al}^{3+}$ ions and covalent cross-linking with glutaraldehyde, whereas the application of toxic cross-linker is not suitable in functional food and the drying process is neglected, which is crucial to the remains of gel structure.

Polyelectrolyte complex formation between macromolecules is another approach which is helpful to bring about improvement in the quality of the above-discussed hydrocolloid-based bead systems. Polyelectrolyte complexes of cationic polymer chitosan and anionic polymers have been extensively reported in the literature. The applicability of chitosan-gellan gum polyelectrolyte complex beads with controlled release properties has been explored [12, 13]. However, the beads prepared with gellan gum and chitosan for encapsulation of metronidazole exhibited poor encapsulation efficiency, and almost all the drugs released within $2 \mathrm{~h}$ in simulated gastric fluid [12].

Although some efforts have been put in understanding the sustained drug release properties of calcium-gellan gum beads or chitosan-gellan gum beads, very few studies have been found describing the formation of protein-loaded chitosan-calcium-gellan gum system. As far as we know, there is no article on one-step formation of chitosan-gellan gum beads with calcium for functional ingredient delivery. This has prompted us to make an attempt to explore the possibility of developing chitosan-calcium-gellan gum beads by one-step process without any other toxic crosslinking agents and to study their potential for oral controlled delivery of water-soluble protein-based functional ingredients.

In this study, chitosan-calcium-gellan gum beads incorporating a model protein (bovine serum albumin, BSA) was prepared by the combination of ionotropic gelation and polyelectrolyte complexation. Various possible physicochemical interactions among formulation components and physical state of albumin in beads were evaluated through Fourier transform infrared spectroscopy, differential scanning calorimetry, and X-ray diffraction analysis. Additionally, the swelling behavior and protein release profile were investigated by mimicking in vitro $\mathrm{pH}$ conditions of the gastrointestinal tract.

\section{Materials and methods}

Materials

Low acyl gellan gum (Kelcogel, food grade) was obtained from George Food Industries Co., Ltd. (Shanghai, China).
Calcium chloride, bovine serum albumin (BSA), and Bradford reagent were purchased from Sinopharm Chemical Reagent Co., Ltd. (Shanghai, China). Partially deacetylated chitosan (approximately $93 \%$ ) with average molecular weight of 100, 000 was acquired from Jinhu Crust product Co., Ltd. (Shandong, China). All other chemicals and reagents used were of analytical grade.

\section{Methods}

\section{Preparation of the chitosan-calcium-gellan gum beads}

Gellan gum was dispersed in deionized water and then heated to $90{ }^{\circ} \mathrm{C}$ with agitation for about 5 min until total dissolution. Core material BSA $(50 \%$ of the dry mass of gellan gum) was then dispersed in the gellan gum solution at around $40{ }^{\circ} \mathrm{C}$ with continuous stirring until a uniform dispersion was obtained [14]. Chitosan solution was prepared by dissolving it with stirring in $3 \%(\mathrm{v} / \mathrm{v})$ acetic acid and mixed with calcium chloride. As the crosslinking solution, the mixed solution of calcium chloride and chitosan was adjusted to $\mathrm{pH} 3.5$ by $0.2 \mathrm{~mol} / \mathrm{L} \mathrm{NaOH}$, which would not affect gellan gum bead formation through ionotropic gelation. The $\mathrm{pH}$ of the cross-linking solution and release medium will affect the charge characteristics of chitosan and gellan gum. At $\mathrm{pH} 3.5$, chitosan is a polycationic polysaccharide and gellan gum is a polyanionic polysaccharide. In this case, chitosan and gellan gum can form a dense polyelectrolyte composite film on the surface of beads under the electrostatic interactions, which could effectively reduce the permeability and the release rate of beads. The gellan gum beads were prepared by the combination of ionotropic gelation and polyelectrolyte complex according to the previous studies $[15,16]$ with some modification. Briefly, aliquots of gellan gum solution $(4 \mathrm{~mL})$ with BSA were extruded dropwise into the gently agitated cross-linking solution with the help of a $10-\mathrm{mL}$ hypodermic syringe fitted with a $20-\mathrm{G}$ needle from $5 \mathrm{~cm}$ distance at room temperature $\left(25^{\circ} \mathrm{C}\right)$ [17]. The beads were formed instantaneously and then cured for $10 \mathrm{~min}$ in chitosancalcium chloride solution with mild agitation, separated by filtration, and washed thrice with deionized water to remove excess calcium chloride, albumin, and chitosan. The obtained beads were dried by freeze-drying $\left(-50{ }^{\circ} \mathrm{C}\right.$, LGJ-10, Four-Ring Science Instru Co., Ltd, China) or oven-drying $\left(37^{\circ} \mathrm{C}\right.$, BGZ-146, Shanghai Boxun Industry \& Commerce CO., Ltd, China) or vacuum-drying ($0.1 \mathrm{MPa}, 37{ }^{\circ} \mathrm{C}$, BZG-6020D, Shanghai Sumsung Experimental Instrument Co., Ltd, China) for $24-48 \mathrm{~h}$ and then kept in a desiccator. Different batches were prepared by varying the formulation parameters (Table 1). All batches were simultaneously prepared in triplicate. 
Table 1 Composition of formulation design

\begin{tabular}{|c|c|c|c|c|}
\hline $\begin{array}{l}\text { Batch } \\
\text { code }\end{array}$ & $\begin{array}{l}\text { Chitosan } \\
\text { concentration } \\
(\% \mathrm{w} / \mathrm{v})\end{array}$ & $\begin{array}{l}\text { Calcium } \\
\text { chloride } \\
\text { concentration } \\
(\mathrm{mol} / \mathrm{L})\end{array}$ & $\begin{array}{l}\text { Gellan gum } \\
\text { concentration } \\
(\% \mathrm{w} / \mathrm{v})\end{array}$ & $\begin{array}{l}\text { Drying } \\
\text { conditions }\end{array}$ \\
\hline A1 & 0.00 & 0.50 & 1.00 & $\begin{array}{l}\text { Oven- } \\
\text { drying }\end{array}$ \\
\hline A2 & 0.25 & 0.50 & 1.00 & $\begin{array}{l}\text { Oven- } \\
\text { drying }\end{array}$ \\
\hline A3 & 0.50 & 0.50 & 1.00 & $\begin{array}{l}\text { Oven- } \\
\text { drying }\end{array}$ \\
\hline A4 & 0.75 & 0.50 & 1.00 & $\begin{array}{l}\text { Oven- } \\
\text { drying }\end{array}$ \\
\hline A5 & 1.00 & 0.50 & 1.00 & $\begin{array}{l}\text { Oven- } \\
\text { drying }\end{array}$ \\
\hline B1 & 0.50 & 0.10 & 1.00 & $\begin{array}{l}\text { Oven- } \\
\text { drying }\end{array}$ \\
\hline B2 & 0.50 & 0.25 & 1.00 & $\begin{array}{l}\text { Oven- } \\
\text { drying }\end{array}$ \\
\hline B3 & 0.50 & 0.50 & 1.00 & $\begin{array}{l}\text { Oven- } \\
\text { drying }\end{array}$ \\
\hline $\mathrm{C} 1$ & 0.50 & 0.25 & 0.75 & $\begin{array}{l}\text { Oven- } \\
\text { drying }\end{array}$ \\
\hline $\mathrm{C} 2$ & 0.50 & 0.25 & 1.00 & $\begin{array}{l}\text { Oven- } \\
\text { drying }\end{array}$ \\
\hline C3 & 0.50 & 0.25 & 1.50 & $\begin{array}{l}\text { Oven- } \\
\text { drying }\end{array}$ \\
\hline D1 & 0.50 & 0.25 & 1.50 & $\begin{array}{l}\text { Vacuum- } \\
\text { drying }\end{array}$ \\
\hline D2 & 0.50 & 0.25 & 1.50 & $\begin{array}{l}\text { Freeze- } \\
\text { drying }\end{array}$ \\
\hline D3 & 0.50 & 0.25 & 1.50 & $\begin{array}{l}\text { Oven- } \\
\text { drying }\end{array}$ \\
\hline
\end{tabular}

\section{Morphology determination}

Morphological observation of surface and cross section of the beads was performed by using a scanning electron microscope (SEM; S-4800, Hitachi, Japan). Before observation, the beads were fixed or sectioned on an aluminum stub followed by coating with gold under vacuum to render them electrically conductive. The micrographs were recorded at an excitation voltage of $1.0 \mathrm{kV}$.

\section{Fourier transform infrared spectroscopy}

Fourier transform infrared (FTIR) spectra of some samples including chitosan, gellan gum-chitosan beads, gellan gum, calcium-gellan gum beads, chitosan-calcium-gellan gum beads, BSA, gellan gum, physical mixture of gellan gum and BSA (mass ratio of 2:1), BSA-loaded calcium-gellan gum beads, and BSA-loaded chitosan-calcium-gellan gum beads were recorded using a FTIR spectrophotometer (NICOLET NEXUS 470, Thermo Electron Corporation, USA). The samples were crushed with potassium bromide to make pellets. The FTIR spectra were scanned in the range of $400-4,000 \mathrm{~cm}^{-1}$, and the resolution was $4 \mathrm{~cm}^{-1}$.

\section{Differential scanning calorimetry}

The differential scanning calorimetry (DSC) measurements were taken using a differential scanning calorimeter (Pyris 1, Perkin-Elmer Corp., Norwalk, CT, USA). Each sample $(1.0-4.0 \mathrm{mg})$ was accurately weighed into an aluminum pan and scanned in hermetically sealed conditions over the temperature range between 30 and $330{ }^{\circ} \mathrm{C}$ at a scanning rate of $10{ }^{\circ} \mathrm{C} / \mathrm{min}$. The characteristic peaks of exotherm and endotherm were recorded. All samples and an empty sealed aluminum pan as reference were kept at $30{ }^{\circ} \mathrm{C}$ for $1 \mathrm{~min}$ before scanning. Nitrogen was used for purging the sample holders at a flow rate of $20 \mathrm{~mL} / \mathrm{min}$. All tests were performed in duplicate.

\section{$X$-ray diffraction studies $(X R D)$}

Samples were filled into a sample holder and exposed to $\mathrm{Cu}$ $\mathrm{K} \alpha$ radiation in a X-ray powder diffractometer (D8, Bruker AXS, German). Each sample was scanned in a continuous mode at a scanning rate of $5 \% \mathrm{~min}$ with the diffraction angle $2 \theta$ from $3^{\circ}<2 \theta<60^{\circ}$.

\section{Determination of encapsulation efficiency and loading capacity}

The protein content in the beads was determined indirectly by measuring the concentration of BSA in the preparation medium and washing solutions by the Bradford method at $595 \mathrm{~nm}$ [1, 18], using a UV-visible spectrophotometer (UV-1600, Mapada Instruments Co., Ltd, China). The encapsulation efficiency (EE, \%) and loading capacity (LC, \%) were calculated according to the following equations:

$\operatorname{EE}(\%)=\left[\left(W_{a}-W_{b}\right) / W_{a}\right] \times 100$

$\mathrm{LC}(\%)=\left[\left(W_{a}-W_{b}\right) / W\right] \times 100$

where $W_{a}$ is the theoretical weight of protein (amounts of protein added into the system), $W_{b}$ is the weight of free protein, and $W$ is the weight of the dried beads.

\section{Swelling characteristics of beads}

The swelling behaviors of beads were studied in simulated gastric fluid (SGF, pH $1.20 .1 \mathrm{~mol} / \mathrm{L} \mathrm{NaCl} / \mathrm{HCl}$ buffer solution), simulated small intestinal fluid (SIF, $0.05 \mathrm{~mol} / \mathrm{L}$ phosphate-buffered saline, PBS, $\mathrm{pH}$ 6.8), and simulated colonic fluid (SCF, $0.05 \mathrm{~mol} / \mathrm{L}$ phosphate-buffered saline, PBS, pH 7.4). Samples of known weight were consecutively dipped in $5 \mathrm{~mL}$ of SGF $(0-2 \mathrm{~h}), \operatorname{SIF}(2-5 \mathrm{~h})$, and 
SCF (5-8 h) at $37{ }^{\circ} \mathrm{C}$. The swollen beads were periodically removed from the swelling medium and weighed at appropriate intervals. The wet weight of the swollen beads was determined by blotting them with filter paper to remove moisture adhering to the surface, immediately. The swelling ratio (SR) of the beads was calculated using the following equation:

$\operatorname{SR}(\%)=\left[\left(W_{t}-W_{0}\right) / W_{0}\right] \times 100$

where $W_{t}$ is the weight of the swollen test sample at appropriate intervals and $W_{0}$ is the absolutely dried weight of beads [19].

The morphological change of beads during swelling in simulated gastrointestinal fluid was observed with an optical microscope (BX51/BX52, Olympus, Japan).

\section{Assessment of in vitro albumin release}

The in vitro BSA release profiles of beads were determined in order to mimic the GIT (i.e., $0-2 \mathrm{~h}$ in SGF, $\mathrm{pH} 1.2$; $2-$ $5 \mathrm{~h}$ in SIF, $\mathrm{pH} 6.8 ; 5-8 \mathrm{~h}$ in SCF, $\mathrm{pH}$ 7.4) from stomach to colon. The BSA-loaded beads were placed into $100-\mathrm{mL}$ conical flask with $20 \mathrm{~mL}$ release medium and incubated at $37 \pm 0.5{ }^{\circ} \mathrm{C}$ under shaking of $50 \mathrm{r} / \mathrm{min}$ [20]. At 30, 60, $120,180,240,300,360,420$, and $480 \mathrm{~min}, 0.3-$ or $0.5-\mathrm{mL}$ aliquot was withdrawn and replenished with an equal volume of fresh dissolution medium. The BSA content in withdrawing samples was analyzed by Bradford method at $595 \mathrm{~nm}$ using a UV-Vis spectrophotometer (UV-1600, Mapada Instruments Co., Ltd, China). The release rate was calculated using the following equation:

Release rate $(\%)=\frac{C_{n} \times V+\sum_{i=0}^{n-1} C_{n-1} \times V_{i}}{W \times \mathrm{LC} \%} \times 100$

where $C_{n}$ is the concentration of BSA in the release medium when samples are taken for the nth time; $V$ is the volume of release medium; $V_{i}$ is the volume of the sample before samples are taken for the nth time.

\section{Albumin release kinetics}

In order to describe the kinetics of albumin release from formulations, zero-order, first-order, Higuchi, and Korsmeyer-Peppas mathematical models were used. Korsmeyer-Peppas mathematical model was used to relate exponentially the albumin release to the elapsed time. It was calculated using the following equation:

$M_{t} / M_{\infty}=K t^{n}$

where $M_{t} / M_{\infty}$ is the fractional solute release at time $t, K$ is a constant which incorporates the structural and geometric characteristics of the device, and $n$ is diffusion exponent which suggests the mechanism of albumin release from spherical polymeric devices [11]. The adequacy of the delivery profiles to the mathematical models is based on the correlation coefficient value $\left(r^{2}\right)$.

\section{Statistical analysis}

All experiments were performed in triplicate, and experimental data are expressed as mean \pm standard error (SE). All statistical analyses were performed using SPSS 13.0 (SPSS Inc., USA). Effects of various parameters on the characteristics of beads were subjected to one-way ANOVA to determine the level of significance between various groups, including chitosan concentration, calcium chloride concentration, gellan gum concentration, and drying conditions. Statistical significance was set at $p<0.05$.

\section{Results and discussion}

Encapsulation properties and morphology of beads

Generally, the encapsulation properties of the beads depended on the dissolution of BSA into the cross-linking solution. The isoelectric point of BSA is around 4.7, and pKa values of gellan gum and chitosan are 3.06 and 6.3, respectively. Beads were generated at $\mathrm{pH} 3.5$ to ensure the maximum interaction between gellan gum and the protein. Under the electrostatic and ionotropic interactions, the beads were adequately formed and the protein was successfully immobilized, as confirmed by the high-efficiency parameter and loading capacity (EE and LC). The diffusion of BSA from beads might also be reduced by controlling the formulation of beads. It was found that the formulation variables showed an obvious influence on the EE and LC of the formulated beads (Table 2). The incorporation of chitosan led to greater encapsulation efficiency and loading capacity, whereas inappropriate concentration was not beneficial to the formation of dense polyelectrolyte complex membrane. Excessive calcium ion concentration would weaken the gel strength of gellan gum, which resulted in the lower EE and LC. Furthermore, the higher the concentration of gellan gum was, the slower the diffusion of BSA from gellan gum solution into the crosslinking solution was. Therefore, the beads had the highest EE $(85.50 \%)$ and LC $(14.85 \%)$ when the concentration of chitosan, calcium ion, and gellan gum were, respectively, $0.50 \%, 0.25 \mathrm{~mol} / \mathrm{L}$, and $1.5 \%$.

After vacuum-drying, the surface morphology of BSAloaded calcium-gellan gum beads and chitosan-calciumgellan gum beads was significantly changed as Fig. 1a, c shown, both of which produced a serious volume phase transition from spherical to irregular ellipsoidal structure and had some roughness and folds on the surface of the beads. During the drying process, many cracks might exist 
Table 2 Release kinetic models, EE, and LC of the beads

\begin{tabular}{|c|c|c|c|c|c|c|c|c|}
\hline \multirow[t]{2}{*}{ Batch code } & \multirow[t]{2}{*}{$\mathrm{EE}(\%)$} & \multirow[t]{2}{*}{$\mathrm{LC}(\%)$} & \multirow[t]{2}{*}{$t_{50 \%}(\mathrm{~h})$} & \multicolumn{4}{|l|}{$r^{2}$} & \multirow[t]{2}{*}{$n$ value } \\
\hline & & & & Zero order & First order & Higuchi & Korsmeyer-Peppas & \\
\hline A1 & $65.07 \pm 1.08^{\mathrm{a}}$ & $7.18 \pm 0.13^{\mathrm{b}}$ & $0.29 \pm 0.01$ & 0.7622 & 0.9477 & 0.8926 & 0.9650 & 0.0807 \\
\hline $\mathrm{A} 2$ & $77.88 \pm 0.82$ & $8.23 \pm 0.14$ & $0.34 \pm 0.01$ & 0.9219 & 0.9699 & 0.9787 & 0.9826 & 0.0979 \\
\hline A3 & $84.44 \pm 2.16$ & $8.72 \pm 0.13$ & $0.39 \pm 0.01$ & 0.9609 & 0.9857 & 0.9951 & 0.9741 & 0.1062 \\
\hline A4 & $79.54 \pm 0.43$ & $8.42 \pm 0.16$ & $0.32 \pm 0.01$ & 0.9018 & 0.9527 & 0.9751 & 0.9933 & 0.0711 \\
\hline A5 & $77.32 \pm 0.69$ & $8.52 \pm 0.87$ & $0.31 \pm 0.01$ & 0.8525 & 0.9578 & 0.9513 & 0.9953 & 0.0844 \\
\hline B1 & $85.39 \pm 0.64^{c}$ & $18.47 \pm 0.66^{\mathrm{d}}$ & $0.32 \pm 0.01$ & 0.9580 & 0.9637 & 0.9573 & 0.9023 & 0.0932 \\
\hline B2 & $83.33 \pm 0.98$ & $12.57 \pm 0.13$ & $0.42 \pm 0.02$ & 0.9932 & 0.9956 & 0.9765 & 0.9088 & 0.1096 \\
\hline B3 & $81.63 \pm 0.88$ & $7.99 \pm 0.46$ & $0.38 \pm 0.03$ & 0.9297 & 0.9690 & 0.9887 & 0.9909 & 0.1030 \\
\hline $\mathrm{C} 1$ & $74.59 \pm 1.15^{\mathrm{e}}$ & $7.50 \pm 0.45^{\mathrm{f}}$ & $0.36 \pm 0.01$ & 0.9502 & 0.9867 & 0.9948 & 0.9831 & 0.1048 \\
\hline $\mathrm{C} 2$ & $81.97 \pm 0.49$ & $12.97 \pm 0.28$ & $0.47 \pm 0.02$ & 0.9803 & 0.9981 & 0.9721 & 0.9176 & 0.1447 \\
\hline $\mathrm{C} 3$ & $85.50 \pm 0.68$ & $14.85 \pm 1.24$ & $2.05 \pm 0.57$ & 0.9888 & 0.9810 & 0.9648 & 0.9157 & 0.1888 \\
\hline D1 & - & - & $4.27 \pm 0.35$ & 0.9351 & 0.9707 & 0.9803 & 0.9798 & 0.3359 \\
\hline D2 & - & - & $3.17 \pm 0.36$ & 0.9263 & 0.9596 & 0.9636 & 0.9536 & 0.2553 \\
\hline D3 & - & - & $2.37 \pm 0.05$ & 0.8683 & 0.9101 & 0.9220 & 0.9170 & 0.1906 \\
\hline
\end{tabular}

Bold values indicate BSA release from beads prepared under different process parameters predominantly followed the corresponding mathematical model as the $\mathrm{r}^{2}$ values were higher than other models

${ }^{\mathrm{a}} p<0.05$ among $0,0.50$ with $0.25,0.75$, and $1.00 \%$ chitosan concentration

${ }^{\mathrm{b}} p<0.05$ between $0 \%$ chitosan concentration with $0.25,0.50,0.75$, and $1.0 \%$ chitosan concentration

${ }^{\mathrm{c}} p<0.05$ between 0.10 and $0.50 \mathrm{~mol} / \mathrm{L}$ calcium chloride concentration

${ }^{\mathrm{d}} p<0.05$ among $0.10,0.25$, and $0.50 \mathrm{~mol} / \mathrm{L}$ calcium chloride concentration

e $p<0.05$ among $0.75,1.00$, and $1.50 \%$ gellan gum concentration

${ }^{\mathrm{f}} p<0.05$ between $0.75 \%$ with 1.00 , and $1.50 \%$ gellan gum concentration

Values are presented as mean $\pm \mathrm{SD} ; n=3$

on the surface of the beads. However, chitosan coating endowed the beads a relatively dense surface with less and smaller cracks compared with that of uncoated beads, which was believed to form harden composite membrane by the cross-linking between chitosan and calcium-gellan gum (Fig. 1b, d). Figure 1e showed a thin surface layer observed in the case of cross section of the chitosan-coated beads. This layer successfully evidenced the formation of the polyelectrolyte complex between chitosan and gellan gum on the bead surface.

Evaluation of the polymer interaction and existence state of albumin in beads

In order to confirm the interaction involved in the formation of beads, the peak variations in pure gellan gum, chitosan, blank calcium-gellan gum beads, blank chitosan-gellan gum beads, and blank chitosan-calcium-gellan gum beads were examined by FT-IR (Fig. 2). In the case of pure gellan gum (Fig. 2c), the characteristic peaks were observed due to H-bonded $\mathrm{O}-\mathrm{H}$ stretch vibration of hydroxyl groups $\left(3,425 \mathrm{~cm}^{-1}\right), \quad \mathrm{C}-\mathrm{H}$ stretch vibration of $\mathrm{CH}_{2}$ group $\left(2,931 \mathrm{~cm}^{-1}\right)$, asymmetric carboxylate anion stretching $\left(1,610 \mathrm{~cm}^{-1}\right)$, symmetric carboxylate anion stretching $\left(1,417 \mathrm{~cm}^{-1}\right)$, and $\mathrm{C}-\mathrm{O}$ stretching $\left(1,033 \mathrm{~cm}^{-1}\right)$. For calcium-gellan gum beads (Fig. 2d), the bands of symmetric carboxylate anion stretching and $\mathrm{C}-\mathrm{O}$ stretching shifted to 1,459 and $1,037 \mathrm{~cm}^{-1}$, respectively. On the other hand, the asymmetric carboxylate anion stretching exhibited two new bands at $1,631.74$ and $1,551.40 \mathrm{~cm}^{-1}$. It may be attributed to the ionic interaction between carboxylic groups of gellan gum and $\mathrm{Ca}^{2+}$ during the formulation of beads [21]. Pure chitosan (Fig. 2a) showed characteristic bands of amide $\left(1,664 \mathrm{~cm}^{-1}\right)$ and amine $\left(1,590 \mathrm{~cm}^{-1}\right)$. The FTIR spectra of chitosan-gellan gum beads (Fig. 2b) showed shifting of amide band to $1,607 \mathrm{~cm}^{-1}$ and amine to $1,560 \mathrm{~cm}^{-1}$. This shift in amine band indicated the change in environment of amine group through its interaction with carboxylate groups on gellan gum [22]. The spectrum of chitosan-calciumgellan gum (Fig. 2e) was similar to that of calcium-gellan gum. Once this bead was coated with chitosan, the band at $1,551 \mathrm{~cm}^{-1}$ was intensified owing to $\mathrm{NH}_{2}$ and $\mathrm{NH}$ of chitosan in chitosan-calcium-gellan gum. The weakened absorption at $1,632 \mathrm{~cm}^{-1}$ indicated the presence of protonated amine group in chitosan [20], and the intensified protonation of most of gellan gum was proved by the changes at 1,632 and $1,460 \mathrm{~cm}^{-1}$ in chitosan-calcium-gellan gum spectra [23]. Therefore, the formation of chitosan- 

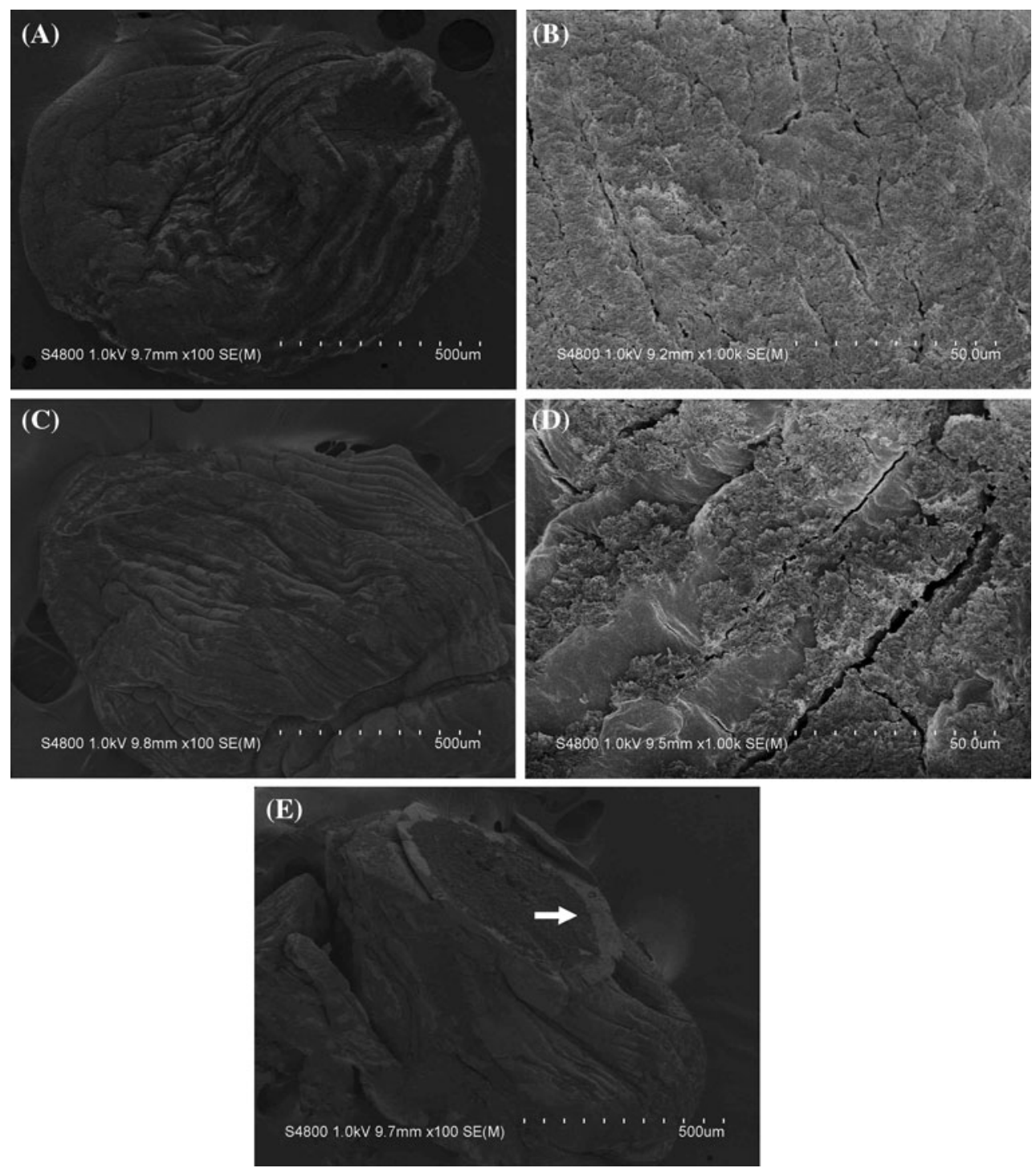

Fig. 1 Scanning electron micrographs of the surface of BSA-loaded chitosan-calcium-gellan gum bead $(\times 100)(\mathbf{a}),(\times 1,000)(\mathbf{b})$; the surface of BSA-loaded calcium-gellan gum bead $(\times 100)($ c),

calcium-gellan gum beads was controlled by the combination of electrostatic and ionic interactions.

The main absorption bands of BSA were listed as follows (Fig. 3a): 1,655 and $1,539 \mathrm{~cm}^{-1}$, corresponding to the amide I band and the amide II band [24], respectively. The characteristic peaks of BSA might be observed in the case of physical mixture of gellan gum and BSA (Fig. 3c), while the peak of amide I shifted from 1,655 to $1,652 \mathrm{~cm}^{-1}$ because of the overlapping between BSA and gellan gum. However, the amide I and amide II peaks of BSA (Fig. 3a) were shifted to 1,637 and $1,548 \mathrm{~cm}^{-1}$ upon the formation of beads (Fig. 3d, e), which could be explained by the existence of interactions (ionic, hydrogen bonding, and/or van der Waals' forces) among formulation components during the complexation/gelation process. $(\times 1,000)(\mathbf{d})$; cross section of BSA-loaded chitosan-calcium-gellan gum bead $(\times 100)(\mathbf{e})$. Arrow indicates the thin surface layer

The physical characteristics of gellan gum, chitosan, and BSA in their pure forms, a physical mixture, and selected formulations were further investigated by calorimetric studies. The thermogram of pure gellan gum was characterized by an endothermic peak at around $121.79{ }^{\circ} \mathrm{C}$ $(\Delta H=53.9,139 \mathrm{~J} / \mathrm{g})$ and a broad exothermic peak at $257.97{ }^{\circ} \mathrm{C}$ (Fig. 4a). The first peak was attributed to a dehydration process [25], while the second one denoted the temperature of gellan gum degradation [21]. However, the two peaks, respectively, shifted to 130.64 and $242.42{ }^{\circ} \mathrm{C}$ in the thermogram of blank calcium-gellan gum beads (Fig. 4d). These changes suggested that in the presence of $\mathrm{Ca}^{2+}$ ions, the "carboxylate- $\mathrm{Ca}^{2+}$-carboxylate" interactions are formed, which is confirmed by a sharp endothermic peak $(\Delta H=225.6,085 \mathrm{~J} / \mathrm{g})$ at $130.64{ }^{\circ} \mathrm{C}$ [25]. 


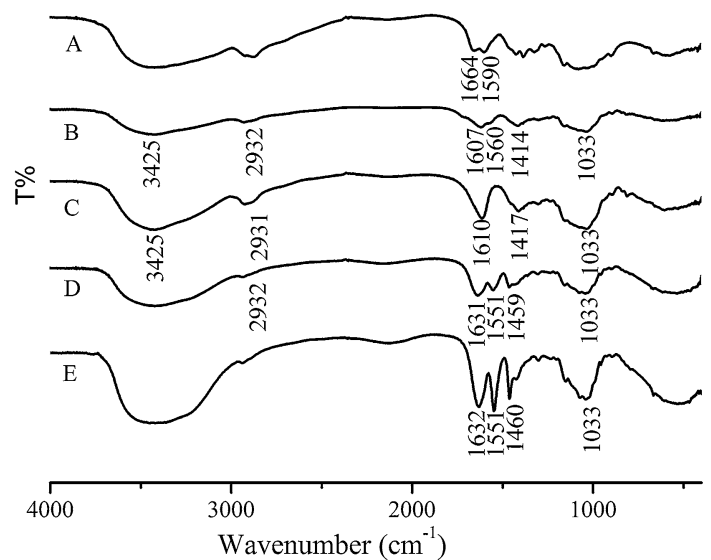

Fig. 2 FTIR spectra of a chitosan; b gellan gum-chitosan beads; c gellan gum; d calcium-gellan gum beads; e chitosan-calcium-gellan gum beads

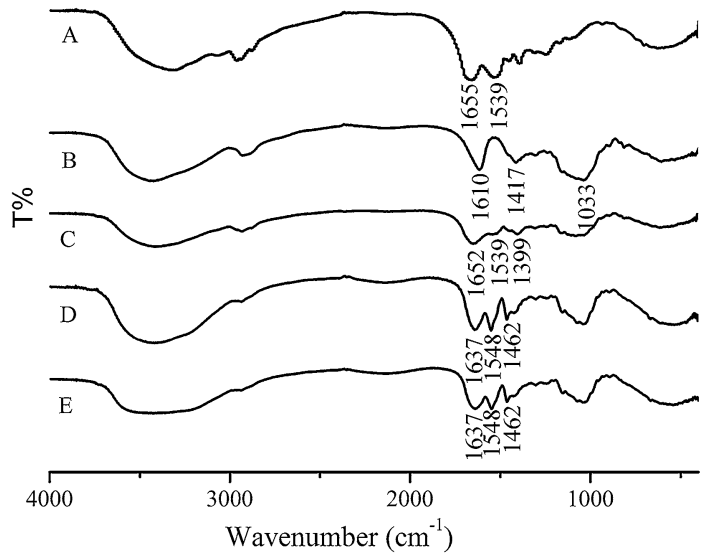

Fig. 3 FTIR spectra of a BSA; b gellan gum; $\mathbf{c}$ physical mixture of gellan gum and BSA (mass ratio of 2:1); d BSA-loaded calciumgellan gum beads; e BSA-loaded chitosan-calcium-gellan gum beads

The thermogram (Fig. 4c) of the chitosan polymer exhibited an endothermic peak at $122.51^{\circ} \mathrm{C}$, attributing to the evaporation of absorbed water, and higher degradation exothermic peaks at $310.82{ }^{\circ} \mathrm{C}[25,26]$, respectively. In the thermograms of the physical mixture of chitosan and gellan gum and blank chitosan-calcium-gellan gum beads, the exothermic peaks were, respectively, transformed in a significantly broad band at the ranges of $243.09-270.91{ }^{\circ} \mathrm{C}$ (Fig. 4b) and $219.59-272.53{ }^{\circ} \mathrm{C}$ (Fig. 4e). Taking into account the endothermic peak at $124.20^{\circ} \mathrm{C}$ in the physical mixture of chitosan and gellan gum and that at $131.46{ }^{\circ} \mathrm{C}$ in chitosancalcium-gellan gum bead (Fig. 4b, e), it was concluded that this peak shift was correlated with the polyelectrolyte interaction between the chitosan and gellan gum [25].

The thermogram of BSA was characterized by two endothermic peaks at 118.12 and $254.72{ }^{\circ} \mathrm{C}$ (Fig. 4f), which corresponded to its denaturation and melting points, respectively. In the physical mixtures containing BSA and gellan gum, the second endothermic peak was supplanted

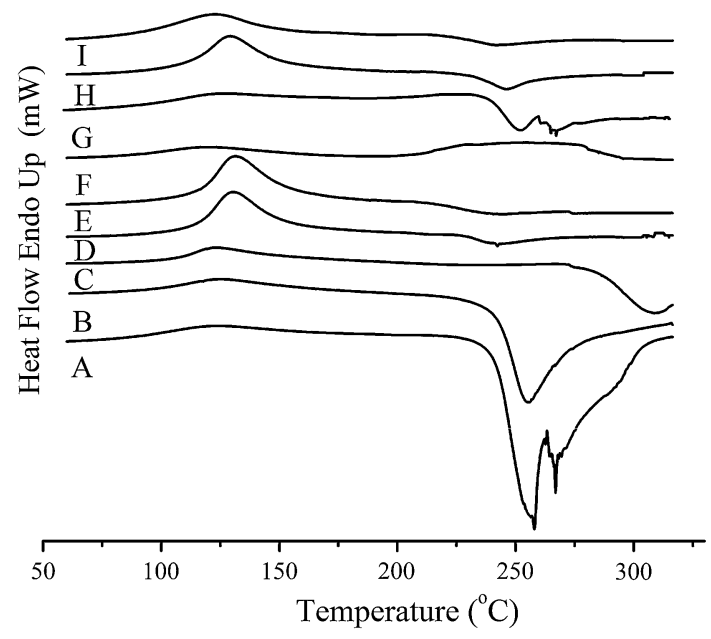

Fig. 4 DSC thermograms of a gellan gum; b physical mixture of gellan gum and chitosan (mass ratio of 1:3); c chitosan; d blank calcium-gellan gum beads; e blank chitosan-calcium-gellan gum beads; $\mathbf{f}$ BSA; $\mathbf{g}$ physical mixture of gellan gum and BSA (mass ratio of 2:1); h BSA-loaded calcium-gellan gum beads; i BSA-loaded chitosan-calcium-gellan gum beads

by an exothermic peak at $252.59{ }^{\circ} \mathrm{C}$ (Fig. $4 \mathrm{~g}$ ). These changes in peak characteristics of BSA and gellan gum could be attributed to change in purity of individual components (because of "dilution effect") and/or a physical interaction between BSA and gellan gum [21]. The absence of BSA endotherm in the thermogram of the physical mixture might be due to the dissolution of the crystalline albumin in the polymer at high temperatures during heating in DSC measurements. The second endothermic peak of BSA disappeared in the thermograms of BSA-loaded calcium-gellan gum beads (Fig. 4h) and BSA-loaded chitosan-calcium-gellan gum beads (Fig. 4i). The thermogram of the blank chitosan-calcium-gellan gum beads (Fig. 4e) was not different from that of BSA-loaded chitosan-calcium-gellan gum beads (Fig. 4i). This suggested that BSA may not recrystallize in the beads through gelation/polyelectrolyte complexation. That was to say that the core material albumin was uniformly dispersed in an amorphous state in the polymer matrix $[4,27]$.

The X-ray diffractograms of gellan gum, BSA, physical mixture of BSA and gellan gum (1:2), BSA-loaded calcium-gellan gum beads, and BSA-loaded chitosan-calcium-gellan gum beads are presented in Fig. 5. There were two strong crystalline peaks in the diffractogram of gellan gum (Fig. 5a), BSA (Fig. 5b), and mixture of BSA and gellan gum (Fig. 5c) at $2 \theta$ of around $9^{\circ}$ and $20^{\circ}$. The raw chitosan (Fig. 5f) also showed one strong crystalline peak at around $20^{\circ}$. However, the crystalline peaks observed in BSA-loaded calcium-gellan gum beads (Fig. 5d) and BSAloaded chitosan-calcium-gellan gum beads (Fig. 5e) almost disappeared. This observation indicated that the crystalline structure of BSA, gellan gum, and chitosan was disrupted 


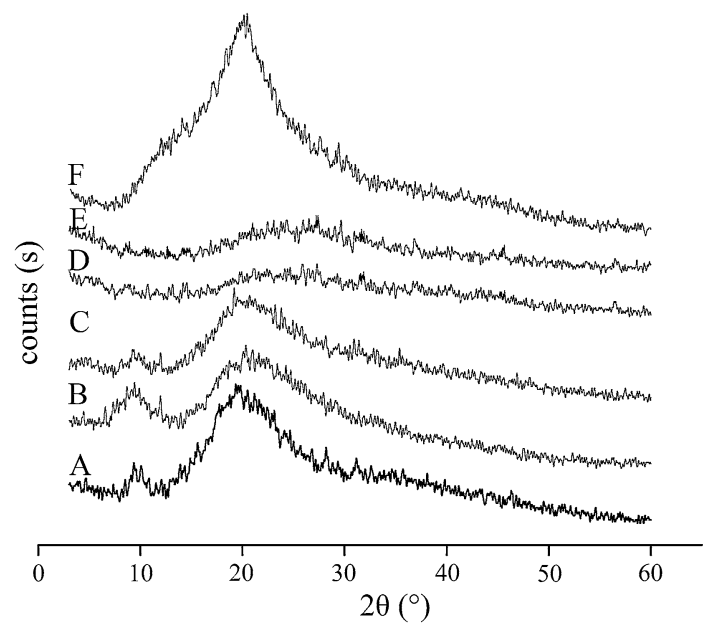

Fig. 5 X-ray diffractograms of pure gellan gum (a); BSA (b); physical mixture of BSA and gellan gum (1:2) (c); BSA-loaded calcium-gellan gum beads (d); BSA-loaded chitosan-calcium-gellan gum beads (e); chitosan (f)

after being combined together in the formulation of beads. That is, a substantial fraction of BSA was present as dissolved form in the polymer matrix. As both amorphous and nanocrystalline forms of BSA were not stable, they would tend to revert to the more thermodynamically stable crystalline form. However, gellan beads incorporating BSA inside its three-dimensional network could serve as stabilizing agent hindering the recrystallization [21].

In vitro albumin release and swelling characteristics of beads

\section{The effect of chitosan concentration}

Cationic polysaccharides-chitosan and anionic polysaccharides-gellan gum can form a polyelectrolyte complex

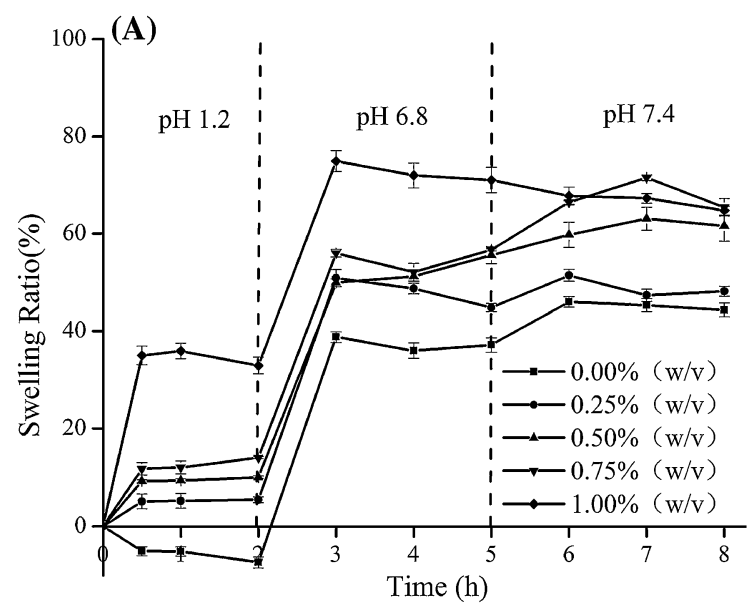

Fig. 6 Effect of chitosan concentration on swelling behavior (a) and release profile (b) of the beads in simulated gastric fluid $(\mathrm{pH} 1.2$, $\mathrm{NaCl} / \mathrm{HCl}$ buffer solution) for $2 \mathrm{~h}$, subsequently in simulated small membrane through electrostatic interaction [28], which is supposed to increase the strength of the calcium-gellan gum beads and decrease their permeability. The results indicated that chitosan played a crucial role in the modulation of the release and swelling of beads during the GI transit (Fig. 6). Figure 6a showed that the swelling ratio of beads increased with increasing chitosan concentration. However, the BSA release percentage of beads was the lowest at $0.50 \%$ of chitosan concentration. Also, BSA exhibited a burst release during the initial $0.5 \mathrm{~h}$, which was up to nearly $60 \%$ (Fig. 6b). In addition, in the absence of chitosan, the dried beads absorbed moisture and stuck together after short-term exposure to the air, while this phenomenon did not appear for the chitosan-calcium-gellan gum beads. It may be able to explain this phenomenon that chitosan-gellan gum polyelectrolyte composite membrane could effectively protect calcium-gellan gum beads from water vapor in the air.

In the absence of chitosan, there was only a threedimensional network structure formed by ionotropic interaction between gellan gum molecules and calcium ions but no chitosan-gellan gum polyelectrolyte complex. At this point, the permeability of beads was greater than that in the presence of chitosan, which also resulted in low encapsulation efficiency and loading capacity of beads. After the raw chitosan was dissolved in an acetic acid solution, a clear and transparent solution was obtained, which suggested that chitosan is fully dissolved and it is not necessary to filter for further purification. At low concentrations $(\leq 0.5 \%)$, chitosan was fully dissolved in acetic acid solution as a form of linear molecules and the solution viscosity was very low. Thus, the linear chitosan molecules could fully disperse on the outer layer of calcium-gellan gum beads and penetrate into the inner mesh of the calcium-gellan gum. The binding between amino groups of chitosan and remaining carboxyl groups of gellan

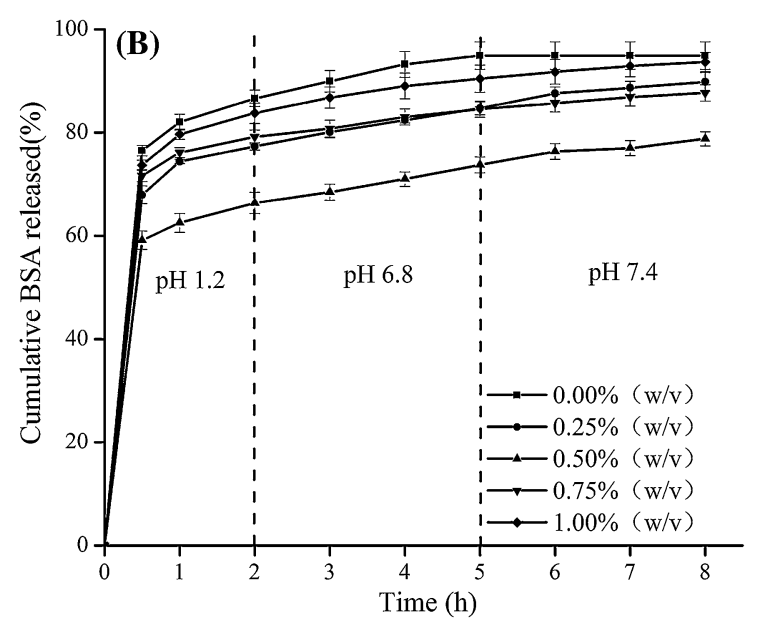

intestinal fluid ( $\mathrm{pH}$ 6.8, phosphate-buffered saline) for $2 \mathrm{~h}$ and in

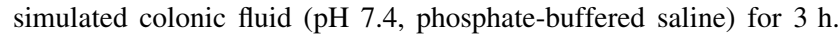
Data were presented as mean \pm SE $(n=3)$ 
gum led to the formation of the dense membrane and greatly reduced the porosity and permeability of beads. The higher the chitosan concentration was, the more significant these effects were. However, the formation of the chitosangellan gum polyelectrolyte complex membrane seemed to be difficult above the concentration of $0.5 \%$. It may be due to the fact that chitosan could not effectively penetrate into the inner mesh of the calcium-gellan gum. In the simulated gastric fluid, carboxylic groups of gellan gum chains on the bead surface converted to $\mathrm{COOH}$ due to the lower medium $\mathrm{pH}$ (1.2) than pKa of gellan gum ( 3.06) [29]. Simultaneously, displacement of calcium ion $\left(\mathrm{Ca}^{2+}\right)$ with $\mathrm{H}^{+}$or $\mathrm{Na}^{+}$occurred at the outer layers of beads. Thus, calciumgellan gum network structure was destroyed, leading to the dissolution of calcium-gellan gum beads and serious burst release of core material [16]. But, the protonation of chitosan amino groups occurred mainly on the outer layer of chitosan-calcium-gellan gum beads in SGF. The release of BSA was mainly controlled by the dissolution of the external chitosan layer as well as the BSA concentration difference on both sides of the semipermeable membrane. The release rate of chitosan-calcium-gellan gum beads was lower than that of the calcium-gellan gum beads. In addition, chitosan at high concentrations $(\geq 0.5 \%)$ could improve the swelling degree and increase the path of BSA diffusion from inner to outer of beads. However, further increasing chitosan concentration would increase the permeability of beads. The beads could swell to a larger extent in alkali medium because of the repulsion of fully negative charged $-\mathrm{COO}^{-}$groups of gellan gum [20].

\section{The effect of calcium chloride concentration}

Some researchers investigated the influence of different divalent cations on the quality of the gellan gum beads

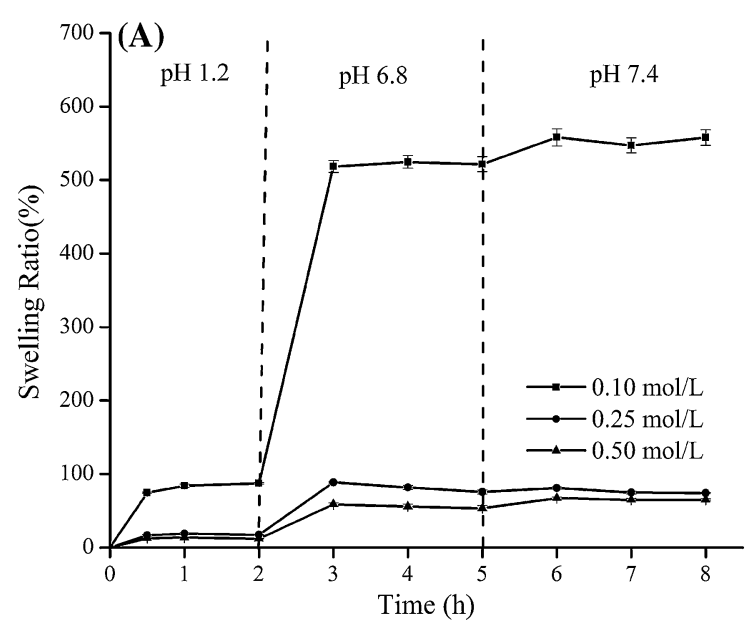

Fig. 7 Effect of calcium chloride concentration on swelling ratio (a) and release profile (b) of the beads in simulated gastric fluid $(\mathrm{pH}$ $1.2, \mathrm{NaCl} / \mathrm{HCl}$ buffer solution) for $2 \mathrm{~h}$, subsequently in simulated and found that the beads prepared with $\mathrm{Ca}^{2+}$ were the best in terms of quality and mechanical strength. The beads prepared with $\mathrm{Zn}^{2+}$ and $\mathrm{Cu}^{2+}$ were fragile and therefore not suitable for bead characterization studies [30]. In the present study, the beads had poor mechanical strength in the absence of $\mathrm{Ca}^{2+}$. Furthermore, it was failing to form particles during the drying process due to a serious collapse of beads. Therefore, the participation of the divalent cation was necessary in the process of gellan gum bead preparation. Figure 7a showed that the swelling ratio of beads prepared at the calcium ion concentration of 0.25 or $0.50 \mathrm{~mol} / \mathrm{L}$ was much lower, compared with those prepared at the calcium ion concentration of $0.1 \mathrm{~mol} / \mathrm{L}$. Figure $7 \mathrm{~b}$ showed that the burst release in the initial $0.5 \mathrm{~h}$ was still very serious but improved, which dropped to $55.71 \%$ at the calcium ion concentration of $0.25 \mathrm{~mol} / \mathrm{L}$.

In aqueous solution, the gelation of gellan was accompanied by a two-step process, namely formation of double helices from random coil chains and an aggregation of pairs of double helices to form a three-dimensional network [14]. However, the carboxyl side chains of gellan gum molecules repelled each other due to electrostatic interactions, which impeded the aggregation of double helices. The "carboxyl-Ca ${ }^{2+}$-carboxyl" junction zones between the gellan gum molecules and $\mathrm{Ca}^{2+}$ could remove the electric repulsion and accelerate the double helices to form a more stable three-dimensional network junction [21]. Therefore, gel strength was enhanced with increasing calcium ion concentration at low concentrations, whereas excess calcium ions may occupy overmuch anion-binding sites of the gellan gum molecules and hinder the orderly aggregation of the double-helix structure of gellan gum, which could weaken the gel strength and increase the permeability of beads [30].

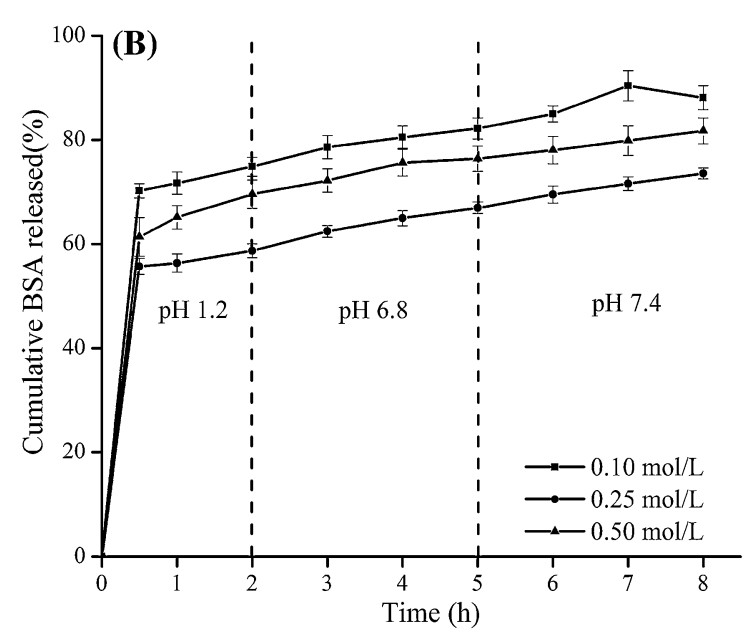

small intestinal fluid ( $\mathrm{pH}$ 6., phosphate-buffered saline) for $2 \mathrm{~h}$ and in

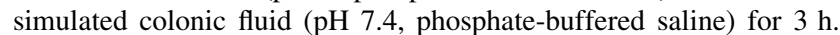
Data were presented as mean \pm SE $(n=3)$ 


\section{The effect of gellan gum concentration}

With increasing gellan gum concentration, the swelling ratio of beads increased while the BSA release of beads decreased (Fig. 8). Verma et al. [14] investigated the effect of gellan gum concentration $(1,3,5 \%$, w/v) on the quality of rifabutin-loaded floating gellan gum beads and obtained similar results about the in vitro release of drug. In this experiment, beads were prepared by dropwise adding of the gellan gum solution into the cross-linking solution through a needle. When the concentration of gellan gum was higher than $1.5 \%$, the solution with high viscosity could not form granulated beads because of the needle clogging. Therefore, no attempt for the high concentration of gellan gum was taken.

Its high viscosity exerted a positive influence on a more compacter three-dimensional network structure and the improvement of gel strength. Moreover, this could create a long and tortuous path for water molecules and BSA to permeate, which led to the improvement of in vitro release effect [4]. Furthermore, the formed thick and dense membrane by chitosan-gellan gum complex reduced the beads' permeability to delay drug release.

\section{The effect of drying conditions}

Figures 9 and 10 showed the swelling and release depending on the type of drying, as a function of incubation time in SGI fluid. The difference in release profile is probably a consequence of structural differences resulting from different water removal mechanisms. The surface of oven-dried beads showed crack. On the contrary, the surface of vacuum-dried beads had no obvious crack and was relatively smooth. With much looser structure and stronger absorption capacity, the freeze-dried beads had a greater swelling ratio compared with the other two. The BSA release was much slower in the vacuum-dried beads than in the oven- and freeze-dried ones (Fig. 10b). It is noteworthy that the cumulative BSA released from the vacuum-dried beads in simulated gastric fluid for $2 \mathrm{~h}$ was just $35 \%$, which was approximately $10 \%$ lower than that of the oven-dried beads (Fig. 10b).

The drying methods were supposed to affect the protein release of beads. During the oven-drying process, a fluid boundary layer was formed on the surface of beads. When water vapor diffused into the air through the boundary layer, the moving speed of the water from the inside to the surface was lower than the evaporation rate of the boundary layer surface, which caused the rupture of the boundary layer water film. The phenomena of hardening, partial cracks, and structural collapse appeared on the surface of beads, which led to the larger permeability and serious albumin burst release during the swelling process of beads. However, the surface hardening and partial cracks could not be found on the surface of beads by vacuum-drying due to the quick diffusion of moisture toward the surface under the large pressure difference between the interior and surface of beads. Consequently, the surface structure of the vacuum-dried beads was more complete and compact compared with the beads obtained by oven-drying. This is in agreement with the greater retention of protein in the vacuum-dried beads. During the freeze-drying process, the wet beads were firstly frozen into a solid and then moisture was removed by the sublimation from the solid state to gas. Because the structure of beads was fixed in the preliminary state, the shape and size of beads remained basically unchanged after drying. The beads were loosely spongy and easy to absorb water and swell. This process was

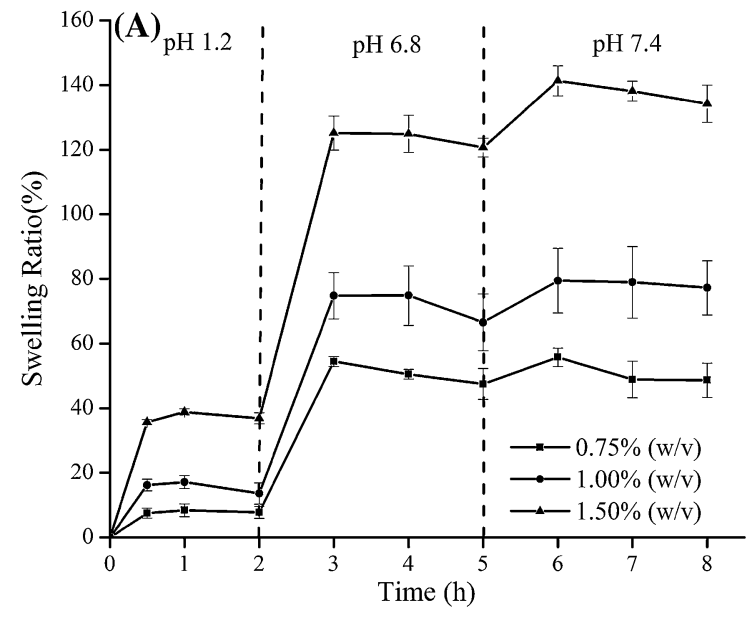

Fig. 8 Effect of gellan gum concentration on swelling ratio (a) and release profile (b) of the beads in simulated gastric fluid $(\mathrm{pH} \mathrm{1.2,}$ $\mathrm{NaCl} / \mathrm{HCl}$ buffer solution) for $2 \mathrm{~h}$, subsequently in simulated small

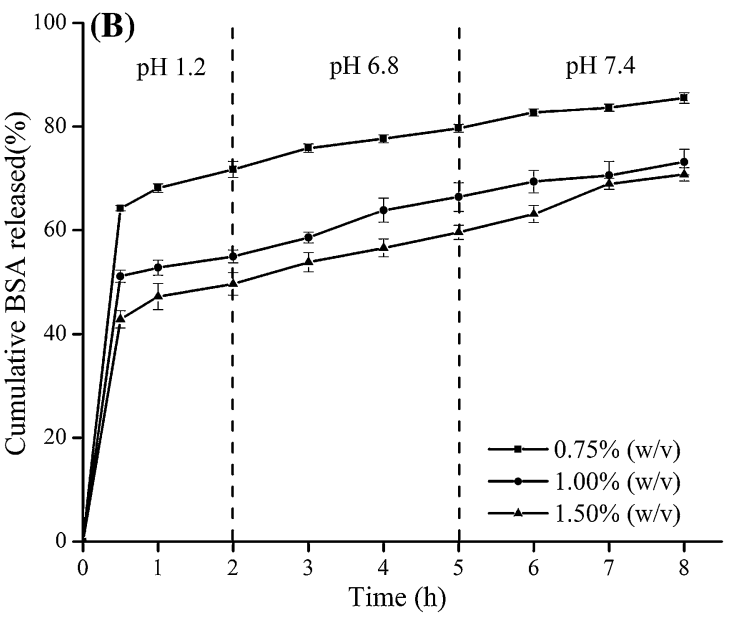

intestinal fluid ( $\mathrm{pH}$ 6.8, phosphate-buffered saline) for $2 \mathrm{~h}$ and in simulated colonic fluid ( $\mathrm{pH} 7.4$, phosphate-buffered saline) for $3 \mathrm{~h}$. Data were presented as mean \pm SE $(n=3)$ 


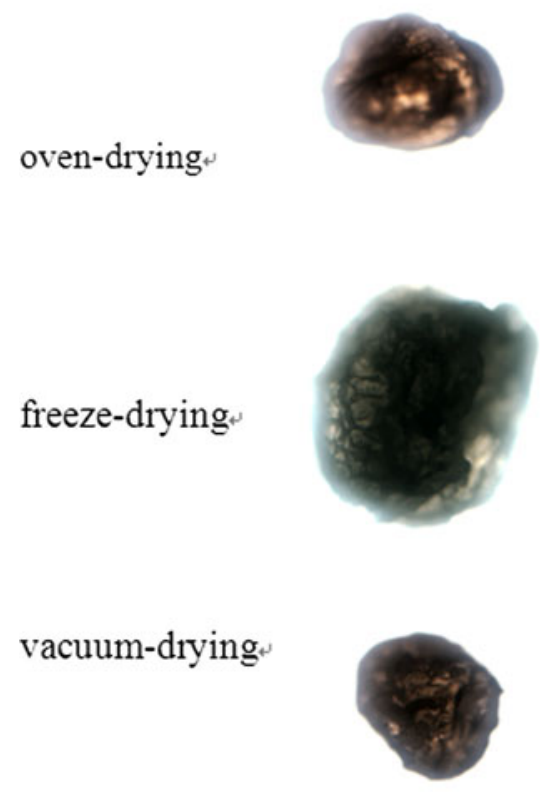

(A)

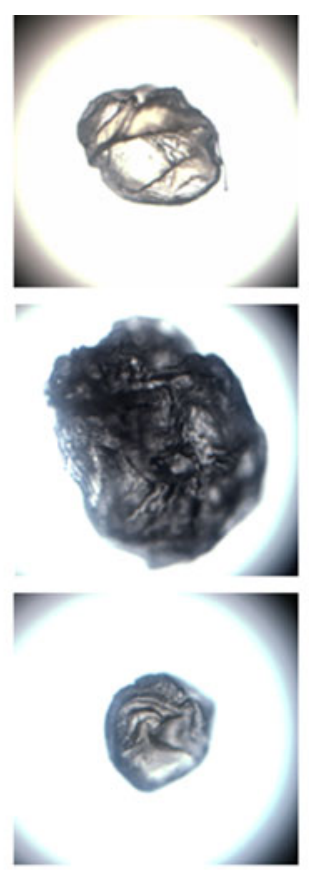

(B)
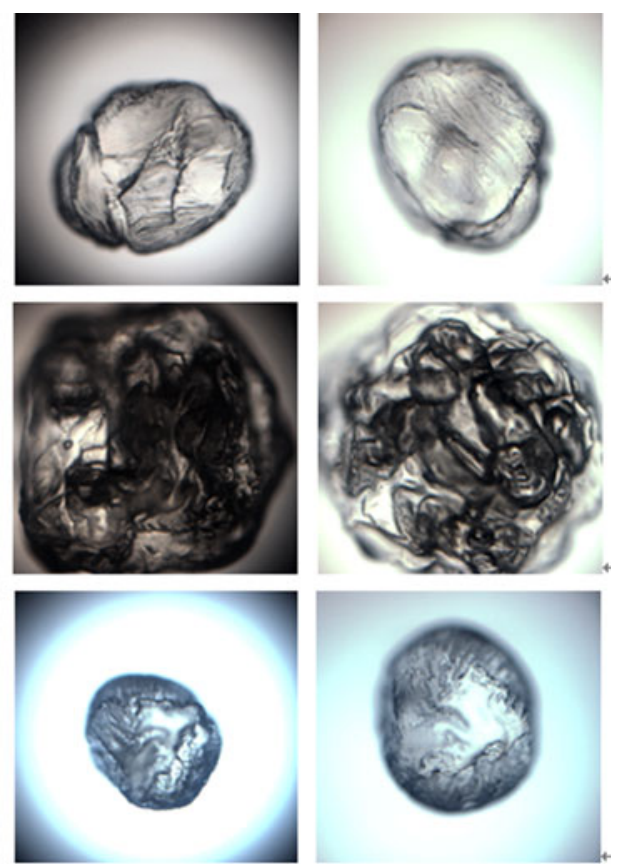

(C)

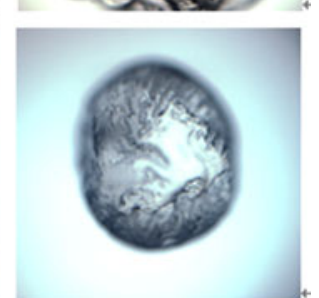

(D)

Fig. 9 Optical micrographs $(\times 40)$ of beads during swelling period. a Before the swelling (dried state); b after incubating in simulated gastric fluid for $2 \mathrm{~h}$; $\mathbf{c}$ in simulated small intestinal fluid for $3 \mathrm{~h}$; $\mathbf{d}$ in simulated colonic fluid for $3 \mathrm{~h}$

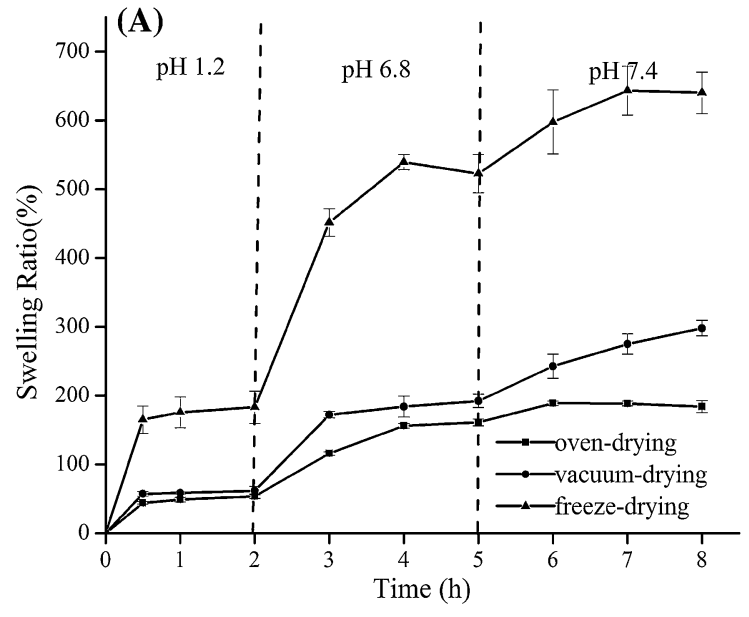

Fig. 10 Effect of drying methods on swelling ratio (a) and release profile (b) of the beads in simulated gastric fluid $(\mathrm{pH} 1.2, \mathrm{NaCl} / \mathrm{HCl}$ buffer solution) for $2 \mathrm{~h}$, subsequently in simulated small intestinal

believed to increase the permeability of beads and accelerate the albumin release, a fact that might not be desirable.

\section{Albumin release kinetics}

In order to compare the albumin release rate, a time point approach was adopted. The values of $t_{50 \%}$ (i.e., time required for the release of $50 \%$ core material load) were calculated (Table 2). The $t_{50 \%}$ in the range from $0.29 \pm 0.01$ to $4.27 \pm 0.60$ indicated that the variation in

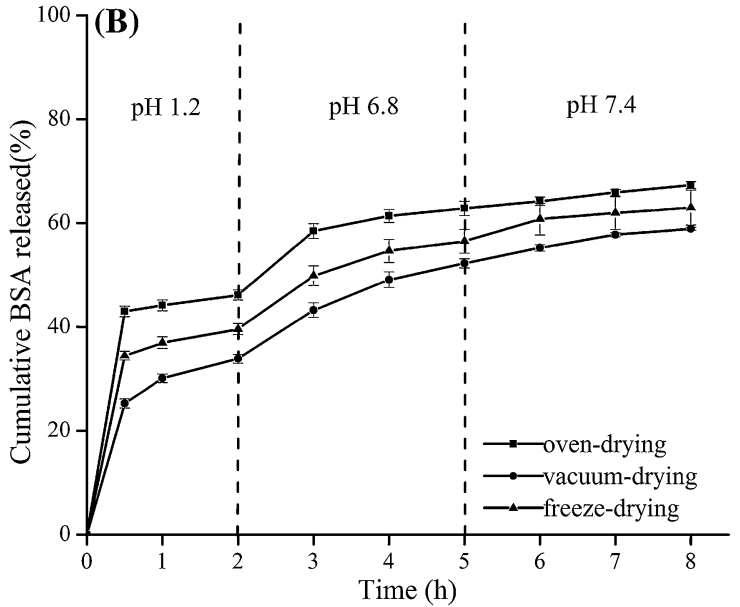

fluid ( $\mathrm{pH}$ 6.8, phosphate-buffered saline) for $2 \mathrm{~h}$ and in simulated colonic fluid ( $\mathrm{pH} 7.4$, phosphate-buffered saline) for $3 \mathrm{~h}$. Data were presented as mean $\pm \mathrm{SE}(n=3)$

formulation parameters resulted in significant difference in the core material release rate, especially the gellan gum concentration and drying conditions. Table 2 also listed the correlation coefficients $\left(r^{2}\right)$ of the release profiles when different mathematical models for the analysis of the release kinetics were applied. For the models studied, the release profiles showed higher correlation coefficients for the Higuchi and Korsmeyer-Peppas models. For the models derived from the Korsmeyer-Peppas equation, it is the $n$ value that characterizes the albumin release 
mechanism. According to the $n$ values (Table 2) that were $<0.43$, the mechanism of albumin release from spherical polymeric devices could be Fickian diffusion through the swelling matrix.

\section{Conclusions}

The chitosan-calcium-gellan gum beads incorporating albumin were prepared by a combination of ionotropic gelation and polyelectrolyte complexation which avoided the use of high-temperature treatment, toxic cross-linker, and organic reagents. The concentration of chitosan, calcium, and gellan gum had an obvious influence on the encapsulation and release properties of beads. The beads through polyelectrolyte complexation of chitosan and gellan gum combined with vacuum drying not only slowed down the albumin burst release in simulated stomach fluid, but also significantly prolong the albumin release time in simulated small intestinal and colonic fluid. The swelling behavior of beads was $\mathrm{pH}$-responsive, and the release of BSA was mainly triggered by a diffusion mechanism in the process of swelling (Fickian diffusion). The amorphous dispersion of albumin in the beads has also been confirmed. Consequently, the beads have the potential for oral controlled delivery application of water-soluble protein-based and water-soluble polypeptide-based functional ingredients which could retain the biological effect of the active ingredients.

Acknowledgments Gellan gum was received as a gift sample from George Food Industries Co., Ltd. This research was financially supported by projects of the National 125 Program of China (2012BAD33B05), the National Natural Science Foundation for Young Scholars of China (31000815), JGA2011015, and PAPD.

Conflict of interest None.

Compliance with Ethics Requirements This article does not contain any studies with human or animal subjects.

Open Access This article is distributed under the terms of the Creative Commons Attribution License which permits any use, distribution, and reproduction in any medium, provided the original author(s) and the source are credited.

\section{References}

1. Lin YH, Liang HF, Chung CK, Chen MC, Sung HW (2005) Physically crosslinked alginate/N, O-carboxymethyl chitosan hydrogels with calcium for oral delivery of protein drugs. Biomaterials 26(14):2105-2113

2. Sinha VR, Kumria R (2001) Polysaccharides in colon-specific drug delivery. Int J Pharm 224(1-2):19-38

3. Chambin O, Dupuis G, Champion D, Voilley A, Pourcelot Y (2006) Colon-specific drug delivery: influence of solution reticulation properties upon pectin beads performance. Int $\mathbf{J}$ Pharm 321(1-2):86-93

4. Agnihotri SA, Jawalkar SS, Aminabhavi TM (2006) Controlled release of cephalexin through gellan gum beads: effect of formulation parameters on entrapment efficiency, size, and drug release. Eur J Pharm Biopharm 63(3):249-261

5. Moslemy P, Neufeld RJ, Millette D, Guiot SR (2003) Transport of gellan gum microbeads through sand: an experimental evaluation for encapsulated cell bioaugmentation. J Environ Manage 69(3):249-259

6. Kang KS, Veeder GT, Mirrasoul PJ, Kaneko T, Cottrell IW (1982) Agar-like polysaccharide produced by a pseudomonas species: production and basic properties. Appl Environ Microb 43(5):1086-1091

7. Singh BN, Trombetta LD, Kim KH (2004) Biodegradation behavior of gellan gum in simulated colonic media. Pharm Dev Technol 9(4):399-407

8. Perez-Campos SJ, Chavarria-Hernandez N, Tecante A, RamirezGilly M, Rodriguez-Hernandez AI (2012) Gelation and microstructure of dilute gellan solutions with calcium ions. Food Hydrocoll 28(2):291-300

9. Rupenthal ID, Green CR, Alany RG (2011) Comparison of ionactivated in situ gelling systems for ocular drug delivery. Part 2: precorneal retention and in vivo pharmacodynamic study. Int $\mathbf{J}$ Pharm 411(1-2):78-85

10. S-1 Cao, X-w Ren, Q-z Zhang, Chen E, Xu F, Chen J, Liu L-C, X-g Jiang (2009) In situ gel based on gellan gum as new carrier for nasal administration of mometasone furoate. Int $\mathrm{J}$ Pharm 365(1-2):109-115

11. Maiti S, Ranjit S, Mondol R, Ray S, Sa B (2011) Al + 3 ion cross-linked and acetalated gellan hydrogel network beads for prolonged release of glipizide. Carbohydr Polym 85(1): 164-172

12. Dixit R, Verma A, Singh UP, Soni S, Mishra AK, Bansal AK, Pandit JK (2011) Preparation and characterization of gellanchitosan polyelectrolyte complex beads. Lat Am J Pharm 30(6):1186-1195

13. Ohkawa K, Kitagawa T, Yamamoto H (2004) Preparation and characterization of chitosan-gellan hybrid capsules formed by self-assembly at an aqueous solution interface. Macromol Mater Eng 289(1):33-40

14. Verma A, Pandit JK (2011) Rifabutin-loaded floating gellan gum beads: effect of calcium and polymer concentration on incorporation efficiency and drug release. Trop J Pharm Res 10(1):61-67

15. Lucinda-Silva RM, Nunes Salgado HR, Evangelista RC (2010) Alginate-chitosan systems: in vitro controlled release of triamcinolone and in vivo gastrointestinal transit. Carbohydr Polym 81(2):260-268

16. Das S, Ng K-Y (2010) Colon-specific delivery of resveratrol: optimization of multi-particulate calcium-pectinate carrier. Int $\mathrm{J}$ Pharm 385(1-2):20-28

17. Das S, Chaudhury A, Ng K-Y (2011) Preparation and evaluation of zinc-pectin-chitosan composite particles for drug delivery to the colon: role of chitosan in modifying in vitro and in vivo drug release. Int J Pharm 406(1-2):11-20

18. Kim TH, Park YH, Kim KJ, Cho CS (2003) Release of albumin from chitosan-coated pectin beads in vitro. Int $\mathrm{J}$ Pharm 250(2):371-383

19. Xu Y, Zhan C, Fan L, Wang L, Zheng H (2007) Preparation of dual crosslinked alginate-chitosan blend gel beads and in vitro controlled release in oral site-specific drug delivery system. Int $\mathbf{J}$ Pharm 336(2):329-337

20. de Souza JRR, de Carvalho JIX, Trevisan MTS, de Paula RCM, Ricardo NMPS, Feitosa JPA (2009) Chitosan-coated pectin beads: characterization and in vitro release of mangiferin. Food Hydrocoll 23(8):2278-2286 
21. Singh BN, Kim KH (2007) Characterization and relevance of physicochemical interactions among components of a novel multiparticulate formulation for colonic delivery. Int $\mathrm{J}$ Pharm 341(1-2):143-151

22. Bigucci F, Luppi B, Cerchiara T, Sorrenti M, Bettinetti G, Rodriguez L, Zecchi V (2008) Chitosan/pectin polyelectrolyte complexes: selection of suitable preparative conditions for colonspecific delivery of vancomycin. Eur J Pharm Sci 35(5):435-441

23. Li X, Xie H, Lin J, Xie W, Ma X (2009) Characterization and biodegradation of chitosan-alginate polyelectrolyte complexes. Polym Degrad Stab 94(1):1-6

24. Wang YX, Li L, Sheng LJ, Song GW, Xu ZS (2011) Spectroscopic study on the inherent binding information of cationic perfluorinated surfactant with bovine serum albumin. J Fluor Chem 132(7):489-494

25. Mladenovska K, Cruaud O, Richomme P, Belamie E, Raicki RS, Venier-Julienne MC, Popovski E, Benoit JP, Goracinova K (2007) 5-ASA loaded chitosan-Ca-alginate microparticles: preparation and physicochemical characterization. Int $\mathrm{J}$ Pharm 345(1-2):59-69
26. Crcarevska MS, Dodov MG, Goracinova K (2008) Chitosan coated $\mathrm{Ca}$-alginate microparticles loaded with budesonide for delivery to the inflamed colonic mucosa. Eur J Pharm Biopharm 68(3):565-578

27. Kulkarni RV, Mangond BS, Mutalik S, Sa B (2011) Interpenetrating polymer network microcapsules of gellan gum and egg albumin entrapped with diltiazem-resin complex for controlled release application. Carbohydr Polym 83(2):1001-1007

28. Amin KAM, Panhuis MIH (2011) Polyelectrolyte complex materials from chitosan and gellan gum. Carbohydr Polym 86(1):352-358

29. Norton AB, Cox PW, Spyropoulos F (2011) Acid gelation of low acyl gellan gum relevant to self-structuring in the human stomach. Food Hydrocoll 25(5):1105-1111

30. Singh BN, Kim KH (2005) Effects of divalent cations on drug encapsulation efficiency of deacylated gellan gum. J Microencapsul 22(7):761-771 